\title{
Door-to-Door Eye Health Education to Improve Knowledge, Attitude, and Uptake of Eyecare Services Among Elderly with Cataracts: A Quasi-Experimental Study in the Central Tropical Region, Myanmar
}

This article was published in the following Dove Press journal: Clinical Ophthalmology

\author{
Kyaw Ko Ko (D) \\ Tepanata Pumpaibool' \\ Maung Maung Myo Wynn ${ }^{2}$ \\ Ye Win $^{2}$ \\ Tin Moe Kyi ${ }^{3}$ \\ Pyae Linn Aung (D) \\ 'College of Public Health Sciences, \\ Chulalongkorn University, Bangkok, \\ 10330, Thailand; ${ }^{2}$ Department of Public \\ Health, Ministry of Health and Sports, \\ Naypyitaw, 15032, Myanmar; \\ ${ }^{3}$ Ophthalmology Ward, General Hospital, \\ Hinthada, I006I, Myanmar
}

Introduction: Cataract-related blindness is routinely reported globally. This study aimed to measure the effect of door-to-door eye health education in improving knowledge and attitude toward cataracts and the use of eyecare services among the elderly residing in a rural area of Naypyitaw Union Territory, Myanmar.

Methods: A quasi-experimental study design that used intervention and control groups was employed in Lewe Township from November 2018 to April 2019. Stratified sampling method was used to select lists of patients diagnosed with cataracts via a township-wide prevalence survey of eye diseases. A total of 56 elderly people with cataracts were involved in each group. The intervention group received door-to-door eye health education for 3 consecutive months. The data were collected using pre- and post-intervention surveys. Descriptive statistics for general characteristics as well as Chi-squared tests and multivariate analysis of variance for significant differences between knowledge and attitude scores of the two groups were analyzed. Results: Both groups represented similarities in socio-economic characteristics, pre-existing knowledge and attitude levels, and eyecare services use. During the baseline study, the mean knowledge score in the intervention group was 7.8 and after the intervention, it increased to 10.67 . Attitude score increased from 4.51 to 7.55 . Among the control group, the scores remained unchanged. For use of eyecare services in the intervention group, $35.7 \%$ of patients sought eyecare services before the intervention, but after, $85.7 \%$ accessed eyecare services. Among them, $78.6 \%$ were satisfied with the treatment outcome. Further, there was a significant difference in knowledge and attitude between the control group and the intervention group ( $p$-value $<0.05$ ), representing a medium effect of the intervention on improving knowledge and attitude level.

Conclusion: Door-to-door eyecare education significantly increased knowledge and attitude toward cataracts and the use of eyecare services among the elderly with cataracts. Intervention might be effective in improving the use of eyecare services and reduction of avoidable blindness due to cataracts.

Keywords: cataract, door-to-door, elderly, eyecare services use, health education, Myanmar

\section{Introduction}

Elderly populations are rapidly increasing worldwide. Currently, one out of ten people is 60 years or above, and by 2050 , the number is predicted to reach one out
Correspondence: Tepanata Pumpaibool College of Public Health Sciences, Chulalongkorn University, Bangkok, 10330, Thailand

Tel +6622188154

Fax +6622556046

Email Tepanata.P@chula.ac.th
Clinical Ophthalmology 2021:15 815-824

submit your manuscript DovePress f $y$ in $>$ http://doi.org/10.2147/OPTH.S287257 
of five. ${ }^{1}$ Further, older age is a major risk factor for eyerelated problems such as blindness, visual impairment, cataracts, glaucoma, and trachoma. ${ }^{2,3}$ Globally, the majority of those with visual impairment are above 50 years of age. ${ }^{4}$ Cataracts, glaucoma, trachoma, onchocerciasis, and vitamin-A deficiency were the most common causes of blindness in the world. ${ }^{2}$ More than 65 million patients with cataracts have been reported, responsible for $51 \%$ of world blindness cases. ${ }^{5}$ Cataracts were correlated with insufficient eyecare knowledge and attitude, poor eyecare seeking practice, and less use of eyecare services. ${ }^{6}$ Therefore, the World Health Organization (WHO) has indicated the need for health promotion interventions in communities. 5

According to data from the Prevention of Blindness Program in Myanmar, the prevalence of blindness totaled $0.6 \%$ followed by $2 \%$ for visual impairment. In addition, $55 \%$ were cataract-related blindness and 70\% comprised cataract-related visual impairment. ${ }^{7}$ The climate conditions of Myanmar, with a subtropical environment, were also risk factors for visual impairment. ${ }^{7}$ Nevertheless, as long as people access regular eyecare services for early diagnosis of cataracts and receive appropriate treatment accordingly, cataracts are likely to be cured and should not lead to subsequent complications such as blindness. Although cataracts could be surgically removed through an operation, in many countries including Myanmar, poor knowledge, negative attitude, and delayed eyecare seeking practice in the community were reported as some of the barriers to accessing the services that exist. 8,9 Appropriate and innovative interventions should be introduced to communities to address these challenges.

Because of fragile physical condition along with increasing age, generally, older people lack access to ordinary health interventions, community health education sessions, and group health talks which are routinely organized in the community. Further, they are mostly unable to contribute to the family income although they remain as household leaders or decision-makers of their respective families in the family members registers. As such, seeking a diagnosis or treatment by themselves is mostly impossible except in the case of serious illness. Therefore, doorto-door interventions might be the best way to educate elderly people with family members including those responsible for the gross family income. Many studies have also investigated the effectiveness of door-to-door health interventions across the world in delivering high- quality services, strengthening community involvement, and spreading important health messages. ${ }^{10-12}$ Therefore, this study aimed to explore the effectiveness of community-based door-to-door eye health education to improve knowledge and attitude toward cataracts and enhance the use of eyecare services among elderly patients with cataracts in Lewe Township, Naypyitaw Union Territory. The result of the study could provide valuable information for reducing the disparities in the primary eyecare interventions of the public health mission.

\section{Materials and Methods Study Design}

A quasi-experimental design that used intervention and control groups was employed. Intervention and control groups were compared at different times. The effectiveness of door-to-door interventions to increase knowledge and attitude regarding cataracts and improving the use of eyecare services among the elderly with cataracts was assessed.

\section{Study Area}

Among eight townships in Naypyitaw Union Territory, Myanmar, Lewe Township was purposely selected as the study area because of its high prevalence of eye diseases, as stated in one study. ${ }^{13}$ It holds a total population of 284,393 and consists of 60 villages. Health care is provided by one 100 -bedded hospital, three station hospitals, and ten rural health centers. To date, there is no record of any cataract intervention study in this township.

\section{Sample Size Calculation}

For the samples, male or female elderly patients, aged over 50 years with confirmed cataracts were eligible to participate in this study. The required sample size was calculated using the following formula. ${ }^{14}$

$$
n=\left[\frac{Z_{1-\frac{\alpha}{2}} \sqrt{\bar{p} \bar{q}\left(1+\frac{1}{r}\right)}+Z_{1-\beta} \sqrt{\bar{p} \bar{q}+\frac{p_{2} q_{2}}{r}}}{\Delta}\right]^{2}
$$

where, $\mathrm{n}=$ desired sample size should be at least 47 for each group, then adding $20 \%$ for drop out, so the sample size became 56 for each group. $Z_{1-\alpha}=$ the standard normal deviation set at 1.96 , corresponding to $95 \%$ confidence level, $Z_{1-\beta}=$ a type II error probability set at 0.84 corresponding to $80 \%$ power, $\mathrm{p}_{1}=$ proportion who have knowledge about cataracts in the control group in rural China $=$ 
$54.5 \%$ or $0.545,{ }^{15} \mathrm{p}_{2}=$ proportion who have knowledge about cataracts in the intervention group in rural China $=$ $87.7 \%$ or $0.877,{ }^{15}$ and $r=$ ratio between sample size of two groups $=1$.

\section{Sampling Methods}

A list of the patients with cataracts diagnosed by previous community-based eye diseases survey ${ }^{16}$ was requested from the respective researchers and the addresses and contact numbers were confirmed as necessary with the help of local administrative officials. A total of 169 patients with cataracts were reported in the list. Depending on the residences of the patients, they were separately listed in eastern, western, northern, and southern parts of the township to create appropriate buffer zones among the locations to minimize any information contamination. After that, east and west areas were assigned as intervention places and the remaining were listed as control areas according to similar patterns of patients' distribution.

Subjects were selected randomly from the list and the sample totaled 56 elderly for each group. Before recruiting the participants, the mental state of the elderly was assessed using the Mini-Mental State Examination (MMSE). ${ }^{17}$ The MMSE was utilized by a previous study in Myanmar to assess the cognitive ability of the elderly. ${ }^{18}$ Those patients with cataracts under normal scores ( 24 to 30 of MMSE) were recruited. All patients with cataracts showed normal mental status. Moreover, patients who were blind in both eyes or had undergone cataract surgeries on both eyes and those who were deaf were excluded.

\section{Door-to-Door Eye Health Education Intervention}

Before commencing the study, advocacy meetings were organized with political and health authorities, local nongovernmental organizations, and the community leaders to explain the purpose of the study to them. To deliver the intervention, two health educators with experience in collecting health information data were selected from the community and trained by the officials from the Prevention of Blindness (PBL) Program, Naypyitaw, together with the researchers. An informal meeting was organized among the researchers and educators to demonstrate the intervention procedures including the proper ways to converse with the elderly.

Door-to-door health education was conducted by the trained health educators once a month for three consecutive months using specifically designed materials on blindness and eye diseases in terms of prevention and treatment, as well as availability, accessibility, and safety of the services. Educational topics varied from month to month. The topics included types of cataracts, awareness of cataracts, poor vision among the elderly, preventive measures, and the role of eyecare to prevent cataracts. These educational materials had been developed in Burmese by the PBL Program and were based on the National Eye Health Education Program. Videos, handouts, education, and communication (IEC) materials such as pamphlets, T-shirts, posters, and calendars with health messages were provided. For the control, group similar to the intervention group, a one-time group health education session that focused on treatment options for cataracts and locations for treatment was held before the intervention.

Before intervention day, selected participants were contacted and a time was scheduled for the intervention. Two household visiting teams were established. Each team included trained educators as well as local people who visited the household of each selected participant. During the very first visit, the team thoroughly explained the procedures of the intervention and encouraged their participation. Other family members were invited to join the education session. Normally, one education session lasted one hour. During one day, two teams completed sessions for an average of 16 participants, and thus the whole intervention took four days within one month.

\section{Study Tools}

The questionnaire was designed according to the WHO cataract survey questionnaire ${ }^{19}$ and other relevant surveys. $^{20,21}$ Next, it was translated to Myanmar using backtranslation methods by two experts from the PBL Program, Myanmar. The questionnaire was used both in pre- and postintervention surveys. The designed questionnaire contained six parts as described in the following paragraphs.

Part 1: General characteristics: this part of the questionnaire comprised 10 questions, covering age, sex, marital status, education level, and monthly income.

Part 2: Social support: this portion of the questionnaire consisted of 20 mini-statements to measure how the elderly received social support which possibly directly or indirectly gave them an advantage to retain good eye health status by preventing cataracts. A 3-point Likert scale model (always, sometimes, and never) ${ }^{22}$ was applied to construct the statements. The measures for the scoring ranged from " 1 " as minimum and " 3 " as maximum. Therefore, the full score for social support ranged from 
" 20 " to " 60 ". Classification of social support: 48 to 60 , good, 36 to 47 , and 20 to 35 , poor social support, according to Bloom's Taxonomy theory. ${ }^{23}$

Part 3: Accessibility, availability, and affordability of eyecare services: this portion of the questionnaire comprised seven questions to measure accessibility, availability, and affordability of eyecare services covering distance, travel time, mode of transportation, cost, and affordability of eyecare services. The conditions for sorting accessibility of eyecare services were "accessible with great difficulties", "accessible with some difficulties" and, "easily accessible".

Part 4: Knowledge about cataracts: this portion of the questionnaire consisted of 13 items containing both positive and negative mini-questions. The overall score for determining knowledge level about cataracts among the elderly ranged from 0 to 13 .

Part 5: Attitude toward cataracts: this part comprised nine items with three possible answers applied to a 3-point Likert scale. ${ }^{22}$ The overall score for determining attitude toward eyecare-seeking behavior ranged from 9 to 27 .

Part 6: Seeking eyecare to prevent cataracts among the elderly: this portion consisted of five questions calculating the extent of seeking eyecare to prevent cataracts among the elderly. The sorting standards of seeking eyecare focused on the basic locations the sought such as seeking eyecare whenever eye problems occurred, seeking or not seeking eyecare, and the location where the elderly received eyecare services within the last year. The classifications for seeking eyecare services were: 1) seeking eyecare services and not seeking eyecare services, 2) seeking eyecare according to referral or not, and 3) seeking eyecare at a referral government hospital or not. Furthermore, there were also questions about satisfaction with eyecare services and outcome of cataract surgery. The exact dates they used eyecare services during the intervention period were also recorded.

Thirty respondents were pre-tested in other similar villages and Cronbach's Alpha coefficient was used for reliability and resulted in 0.83 . To test the internal consistency of the questions with dichotomous choices, KuderRichardson formula 20 (KR20) was also calculated and it was satisfactory at 0.86 . Moreover, the final version of the questionnaire was reviewed and approved by the national program.

\section{Data Collection and Processing}

Before the intervention, a baseline measurement was conducted to compare preexisting conditions in both intervention and control groups. Another follow-up measurement was performed immediately after a three-month intervention in both groups to assess the changes in knowledge and attitude. An end-line survey at six months was conducted to summarize the numbers of eyecare services used in both groups.

To proceed with data collection, two research assistants were hired and trained for two days regarding the questionnaire, data collection procedures, practice under real conditions and maintaining human ethics. The assistants visited households of selected participants using a predefined sample list. They also requested the help of locals to accompany them during interview visits to the households. Normally, an interview lasted about 30 minutes. The researcher checked all the answers to the questionnaires daily during the data collection time and when data were found to be missing, they checked with data collectors who recollected the data the following day.

Collected data were coded and entered using Epidata (Version 3.1), and analyzed with Statistical Package for the Social Sciences (SPSS, Version 23). Frequencies, proportions, mean and standard deviation for descriptive analysis were calculated to describe socio-demographic factors, knowledge, attitude, and practice of the elderly regarding cataracts. Chi-squared tests were used to test the homogeneity between intervention and control groups for categorical variables. Multivariate analysis of variance (MANOVA) was applied to analyze the mean differences of knowledge and attitude scores among intervention and control groups along with the effect size of the intervention. Comparison of using eyecare services between the two groups was also analyzed by using Chi-squared test and patients' satisfaction was with descriptive statistics.

\section{Ethical Consideration}

Request for ethical approval for this study was submitted and approved by the Institutional Review Board, Department of Medical Research, Lower Myanmar, with approval number: Ethics/DMR/2018/ 144. The study was conducted in accordance with the Declaration of Helsinki.

The interviewers explained the objectives and activities of the study which would be done with the participants and obtained informed consent from the respondents. 


\section{Results}

\section{Preexisting Characteristics of the Participants}

To explore the potential confounding factors of participants toward implemented interventions, their characteristics as well as socio-economic conditions were compared. As described in Table 1, all the constructed variables were

Table I Comparison of General Characteristics Between Intervention and Control Groups

\begin{tabular}{|c|c|c|c|c|c|}
\hline \multirow[t]{2}{*}{ Descriptions } & \multicolumn{2}{|c|}{$\begin{array}{l}\text { Control } \\
(n=56)\end{array}$} & \multicolumn{2}{|c|}{$\begin{array}{l}\text { Intervention } \\
(n=56)\end{array}$} & \multirow[t]{2}{*}{ p-value } \\
\hline & $\mathbf{n}$ & (\%) & $\mathbf{n}$ & (\%) & \\
\hline \multicolumn{6}{|l|}{ Age (years) } \\
\hline $50-65$ & 16 & 28.6 & 12 & 21.4 & 0.383 \\
\hline$>65$ & 40 & 71.4 & 44 & 78.6 & \\
\hline \multicolumn{6}{|l|}{ Sex } \\
\hline Male & 23 & 41.1 & 21 & 37.5 & 0.699 \\
\hline Female & 33 & 58.6 & 35 & 62.5 & \\
\hline \multicolumn{6}{|l|}{ Marital status } \\
\hline Single & 10 & 17.9 & II & 19.6 & 0.928 \\
\hline Married & 27 & 48.2 & 25 & 44.6 & \\
\hline Widow/widower & 19 & 33.9 & 20 & 35.7 & \\
\hline \multicolumn{6}{|l|}{ Education } \\
\hline Illiterate & 10 & 17.9 & II & 19.6 & 0.995 \\
\hline Primary & 29 & 51.8 & 28 & 50.0 & \\
\hline Secondary & 8 & 14.3 & 7 & 12.5 & \\
\hline High school & 2 & 3.6 & 2 & 3.6 & \\
\hline Graduated & 0 & 0.0 & 0 & 0.0 & \\
\hline Other & 7 & 12.5 & 8 & 14.3 & \\
\hline \multicolumn{6}{|l|}{ Occupation } \\
\hline Housework & 24 & 42.9 & 28 & 50.0 & 0.981 \\
\hline Farmer & 21 & 37.5 & 17 & 30.4 & \\
\hline Retired & I & 1.8 & I & 1.8 & \\
\hline Labor & 6 & 10.7 & 6 & 10.7 & \\
\hline Unemployed & I & 1.8 & I & 1.8 & \\
\hline Other & 3 & 5.4 & 3 & 5.4 & \\
\hline \multicolumn{6}{|c|}{ Household members } \\
\hline$<5$ & 44 & 78.6 & 35 & 62.5 & 0.062 \\
\hline$\geq 5$ & 12 & 21.4 & 21 & 37.5 & \\
\hline \multicolumn{6}{|c|}{ Monthly family income (MMK*) } \\
\hline$<500,000$ & 39 & 69.6 & 41 & 73.2 & 0.676 \\
\hline$\geq 500,000$ & 17 & 30.4 & 15 & 26.8 & \\
\hline
\end{tabular}

(Continued)
Table I (Continued).

\begin{tabular}{|c|c|c|c|c|c|}
\hline \multirow[t]{2}{*}{ Descriptions } & \multicolumn{2}{|c|}{$\begin{array}{l}\text { Control } \\
(n=56)\end{array}$} & \multicolumn{2}{|c|}{$\begin{array}{l}\text { Intervention } \\
(n=56)\end{array}$} & \multirow[t]{2}{*}{ p-value } \\
\hline & $\mathbf{n}$ & (\%) & $\mathbf{n}$ & (\%) & \\
\hline \multicolumn{6}{|c|}{ Presence of underlying disease(s) } \\
\hline Yes & 31 & 55.4 & 29 & 51.8 & 0.705 \\
\hline No & 25 & 44.6 & 27 & 48.2 & \\
\hline \multicolumn{6}{|c|}{ Duration of cataracts (years) } \\
\hline$<1$ & 9 & 16.1 & 10 & 17.9 & 0.968 \\
\hline$\geq 1$ & 42 & 75.0 & 41 & 73.2 & \\
\hline Do not know & 5 & 8.9 & 5 & 8.9 & \\
\hline \multicolumn{6}{|c|}{ Previous knowledge about cataracts } \\
\hline Yes & 36 & 64.3 & 32 & 57.1 & 0.439 \\
\hline No & 20 & 35.7 & 24 & 42.9 & \\
\hline
\end{tabular}

Notes: *USDI MMK I500. Degree of freedom for Chi-squared test=I.

similar between the two groups, showing p-values at $>0.05$. Social support, availability of eyecare services, affordability of travel and service costs and accessibility to eyecare services in each group were compared in Table 2. The results suggested insignificant differences between intervention and control groups at p-value $>0.05$.

\section{Changes in Knowledge, Attitude, and Use of Eyecare Services After Intervention}

Before and after the intervention, multivariate analysis of variance (MANOVA) was calculated to identify group differences based on the intervention; significant differences in change over time were noted between the two groups in knowledge and attitude (Table 3). Before the intervention, the mean knowledge score was 7.80 in the intervention group and 7.61 in the control group. After the intervention, the mean knowledge score was 10.67 in the intervention group and 7.63 in the control group. Significant differences over time were also noted in attitude scores between the two groups $(p=0.032)$. The mean score of attitudes was 7.55 in the intervention group and 4.62 in the control group after the intervention, whereas the score was 4.51 in the intervention group and 4.53 in the control before the intervention. After calculating the effect size of intervention on both knowledge score and attitude score between the two groups before and after the intervention, the value 0.167 for knowledge and 0.236 for attitude revealed that there was a medium effect of the intervention on 
Table 2 Comparison of Social Support, Accessibility, Availability, and Affordability of Eyecare Services Between Intervention and Control Groups

\begin{tabular}{|c|c|c|c|c|c|}
\hline \multirow[t]{2}{*}{ Descriptions } & \multicolumn{2}{|c|}{$\begin{array}{l}\text { Control } \\
(n=56)\end{array}$} & \multicolumn{2}{|c|}{$\begin{array}{l}\text { Intervention } \\
(n=56)\end{array}$} & \multirow[t]{2}{*}{ p-value } \\
\hline & $\mathbf{n}$ & (\%) & $\mathbf{n}$ & (\%) & \\
\hline \multicolumn{6}{|l|}{ Social support } \\
\hline Good & 8 & 14.3 & 5 & 8.9 & 0.376 \\
\hline Poor & 48 & 85.7 & 51 & 91.1 & \\
\hline \multicolumn{6}{|c|}{ Availability of eyecare services } \\
\hline \multicolumn{6}{|c|}{ Distance to travel to eyecare services (miles) } \\
\hline$<10$ & 27 & 48.2 & 33 & 58.9 & 0.256 \\
\hline$\geq 10$ & 29 & 51.8 & 23 & 41.1 & \\
\hline \multicolumn{6}{|c|}{ Transportation route } \\
\hline Convenient & 48 & 85.7 & 50 & 89.3 & 0.815 \\
\hline Inconvenient & 8 & 14.3 & 6 & 10.7 & \\
\hline \multicolumn{6}{|l|}{ Affordability } \\
\hline \multicolumn{6}{|c|}{ Affordable travel } \\
\hline Yes & 50 & 89.3 & 51 & 91.1 & 0.751 \\
\hline No & 6 & 10.7 & 5 & 8.9 & \\
\hline \multicolumn{6}{|c|}{ Affordable service costs } \\
\hline Yes & 37 & 66.1 & 40 & 71.4 & $0.54 I$ \\
\hline No & 19 & 33.9 & 16 & 28.6 & \\
\hline \multicolumn{6}{|c|}{ Easy access to eyecare services } \\
\hline Yes & 23 & $4 I . I$ & 21 & 37.5 & 0.699 \\
\hline No & 33 & 58.9 & 35 & 62.5 & \\
\hline
\end{tabular}

Note: Degree of freedom for Chi-squared test=I.

improving knowledge and attitude level and it might have reliable impact on a targeted population.

As a secondary outcome measure, the use of eyecare services among the participants was assessed. Along with the increasing knowledge and attitude levels among the participants within the intervention period, their behaviors toward the use of eyecare services for possible treatment at referral health centers are listed in Table 4. Before delivering the intervention, all participants received a diagnosis of cataracts and were referred to the locations to receive treatment. Before the intervention, the results revealed that eyecare use practices between intervention and control groups were similar and did not differ significantly $(\mathrm{p}=$ 0.392). Only $8.9 \%$ of participants in the control group sought eyecare services while $16.1 \%$ in the intervention group used services.
After the intervention, the use of eyecare services among intervention and control groups was reassessed and the results described a large increment in the intervention group. More than $85 \%$ in the intervention group had used eyecare services after or within the intervention. Only $40 \%$ from the control group sought and received eyecare treatment. Figure 1 reveals the numbers of eyecare services used during the intervention period. Both groups were advised to keep to the follow-up instructions given by the researcher. About $75 \%$ followed the referral.

\section{Patients' Satisfaction Toward Eyecare Services}

The patients' satisfaction toward eyecare services was a factor related to the participants' referred to or using the services. Therefore, patients' satisfaction was assessed among pooled samples in both intervention and control groups, as shown in Table 5. First, most patients preferred to seek eyecare at government hospitals $(82.9 \%)$ followed by private eye clinics (12.9\%). Among those who had undergone any type of eye operation, about $70 \%$ were satisfied with the services received and $78.6 \%$ were satisfied with the results or outcomes of the operation. However, there was no difference in patient satisfaction according to gender.

\section{Discussion}

The results of the study showed no significant difference between the two groups when comparing social support, availability of eyecare services, affordability, and accessibility. This could be because they were from the same township and were all from rural areas. Moreover, their family income and number of family members did not differ. Significantly, most elderly people from each group only had poor social support, $91.1 \%$ in the intervention group and $85.7 \%$ in the control. However, these elderly with poor support believed that they could afford travel. Moreover, $71.4 \%$ from the intervention and $66.1 \%$ from the control could also afford the treatment cost. On the other hand, only $37.5 \%$ from the intervention and $41.1 \%$ from the control group thought that they could easily access eyecare services. This could be because social support played a significant role even when they reported convenient services and affordable cost. Otherwise, older people could also be afraid of visiting hospitals and clinics without any family members or support. 
Table 3 Comparison of Knowledge and Attitude Between Intervention and Control Groups Before and After Intervention

\begin{tabular}{|c|c|c|c|c|c|c|c|}
\hline \multirow[t]{2}{*}{ Description } & \multicolumn{2}{|l|}{ Before Intervention } & \multicolumn{2}{|l|}{ After Intervention } & \multirow[t]{2}{*}{ F Stat } & \multirow[t]{2}{*}{ p-value } & \multirow[t]{2}{*}{ Effect Size } \\
\hline & Control (Mean士SD) & $\begin{array}{l}\text { Intervention } \\
\text { (Mean士SD) }\end{array}$ & Control (Mean \pm SD) & $\begin{array}{l}\text { Intervention } \\
\text { (Mean士SD) }\end{array}$ & & & \\
\hline Knowledge & $7.6 I \pm 2.7$ & $7.80 \pm 2.6$ & $7.63 \pm 2.3$ & $10.67 \pm 1.2$ & 30.56 & $<0.001 *$ & 0.167 \\
\hline Attitude & $4.53 \pm 2.1$ & $4.5 I \pm 2.0$ & $4.62 \pm 1.5$ & $7.55 \pm 1.0$ & 2.93 & $0.032 *$ & 0.236 \\
\hline
\end{tabular}

Note: *Significance at multivariate analysis with $\mathrm{p}$-value $<0.05$.

Table 4 Comparison of Using Eyecare Services Among Intervention and Control Groups Before and After Intervention

\begin{tabular}{|c|c|c|c|c|c|}
\hline \multirow[t]{2}{*}{ Descriptions } & \multicolumn{2}{|c|}{ Control } & \multicolumn{2}{|c|}{ Intervention } & \multirow[t]{2}{*}{ p-value } \\
\hline & $\mathbf{n}$ & (\%) & $\mathbf{n}$ & (\%) & \\
\hline \multicolumn{6}{|l|}{ Before intervention } \\
\hline Use of eyecare services & $(n=56)$ & & $(n=56)$ & & \\
\hline Yes & 5 & 8.9 & 9 & 16.1 & 0.392 \\
\hline No & 51 & 91.1 & 47 & 83.9 & \\
\hline \multicolumn{6}{|l|}{ After intervention } \\
\hline Use of eyecare services & $(n=56)$ & & $(n=56)$ & & \\
\hline Yes & 22 & 39.3 & 48 & 85.7 & $<0.001 *$ \\
\hline No & 34 & 60.7 & 8 & 14.3 & \\
\hline Followed referral & $(n=22)$ & & $(n=48)$ & & \\
\hline Yes & 17 & 77.3 & 36 & 75.0 & 0.837 \\
\hline No & 5 & 22.7 & 12 & 25.0 & \\
\hline
\end{tabular}

Notes: *Significance at $p<0.05$. Degree of freedom for Chi-squared test $=1$.

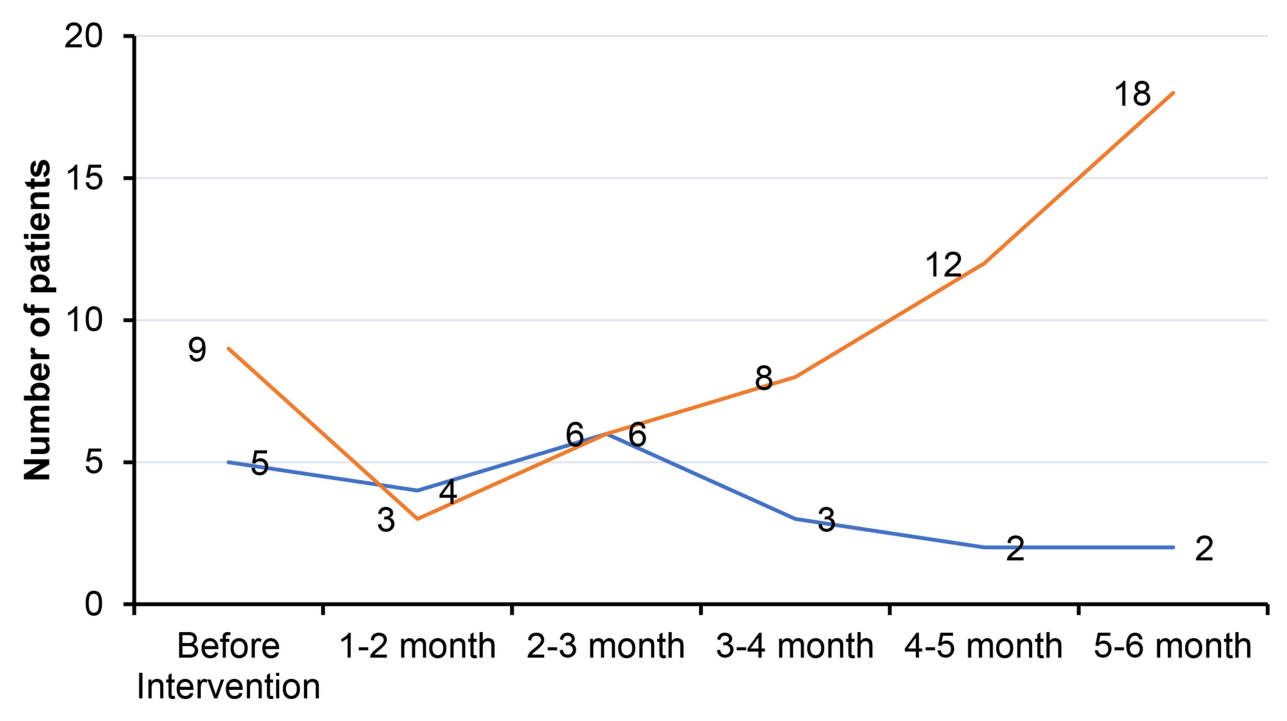

- Control - Intervention

Figure I Use of eyecare services among elderly people with cataracts. 
Table 5 Patients' Satisfaction Toward Eyecare Services $(n=70)$

\begin{tabular}{|c|c|c|c|c|c|c|}
\hline \multirow[t]{2}{*}{ Descriptions } & \multicolumn{2}{|c|}{$\begin{array}{l}\text { Male } \\
(n=32)\end{array}$} & \multicolumn{2}{|c|}{$\begin{array}{l}\text { Female } \\
(n=38)\end{array}$} & \multicolumn{2}{|c|}{ Total } \\
\hline & $\mathbf{n}$ & (\%) & $\mathbf{n}$ & (\%) & $\mathbf{n}$ & (\%) \\
\hline \multicolumn{7}{|c|}{ First place to seek eyecare } \\
\hline Government hospital & 26 & 81.2 & 32 & 84.1 & 58 & 82.9 \\
\hline Private eye clinic & 5 & 15.6 & 4 & 10.5 & 9 & 12.9 \\
\hline $\begin{array}{l}\text { Drug store/pharmacy/ } \\
\text { optical shop }\end{array}$ & 1 & 0.3 & 1 & 0.3 & 2 & 2.9 \\
\hline Traditional healing & 0 & - & I & 0.3 & I & 1.3 \\
\hline \multicolumn{7}{|c|}{ Satisfaction toward eyecare services } \\
\hline \multicolumn{7}{|c|}{ Operation/treatment performed } \\
\hline Satisfied & 23 & 71.9 & 26 & 68.4 & 49 & 70.0 \\
\hline Unsatisfied & 9 & 28.1 & 12 & 31.6 & 21 & 30.0 \\
\hline \multicolumn{7}{|l|}{ Outcome/results } \\
\hline Satisfied & 27 & 84.4 & 28 & 73.7 & 55 & 78.6 \\
\hline Unsatisfied & 5 & 15.6 & 10 & 26.3 & 15 & 21.4 \\
\hline
\end{tabular}

Before starting the intervention, the underlying knowledge and attitude scores were tested in both groups and did not significantly differ. After three months' intervention, the scores significantly differed between the two groups. Knowledge and attitude scores were significantly higher in the intervention than in the control group. To further explore the changes in knowledge and attitude scores in each group, within-group comparisons also justified the results that in the intervention group, the scores appeared high after the intervention, showing significant change. These results confirmed that door-to-door consecutive health education was better than group health education. As a result of repeated information including interesting videos and user-friendly pamphlets, older people demonstrated an awareness of correct information about cataracts. This result is in line with a study done in Korea, ${ }^{24}$ in which increased knowledge and attitude levels were achieved by door-to-door health education intervention. The national program should train more human resources like adding some more activities to village health volunteers and manage improved distribution to rural and remote areas for eye health education and eyecare support.

The use of eyecare services at referral health centers was measured as a secondary outcome in both groups accompanied by increasing knowledge and attitude levels during or after six months' intervention period. Before the intervention, the eyecare use practices between the two groups did not differ significantly. This might be because of insufficient or wrong information about cataracts and their cultural beliefs that eye problems are due to aging and are unavoidable. On the other hand, even when they could easily access services and had a sufficient budget for eyecare, as already mentioned previously, they did not have sufficient support to access eyecare services. This result was aligned with another study conducted in Sri Lanka $^{25}$ where sufficient knowledge, attitude, and good social support were required for patients with cataracts in order to seek eyecare services.

Immediately after the intervention and three months after the intervention, the use of eyecare services between the two groups was re-examined and an increase was observed in the intervention group. This occurred because the intervention group received repeated information in more interesting ways even when the information was the same. Similar results could be found in another study where the results showed the good effect of door-to-door eye health education. ${ }^{26}$ Among the patients with cataracts who used eyecare services in both groups, many of them went to the government hospitals (referral hospital) as they were informed before starting the intervention to seek eyecare using a referral letter. Some patients sought eyecare at private eye clinics and pharmacies, and a few were treated using traditional healing methods. This situation was similar to a study conducted in Burkina $\mathrm{Faso}^{27}$ in which before health education, most of the elderly did not know the etiology of cataracts and modern treatment methods, while some believed health workers or village health volunteers should come as traditional healers.

Moreover, most of the patients with cataracts who used eyecare services in both groups were satisfied with the operation or treatment performed. A similar result was found in another study in Western Canada ${ }^{28}$ where most of the patients with cataracts were satisfied with the operation or treatment received, but just not with the length of time being on the waiting list. Regarding surgical outcome, $78.6 \%$ were satisfied. This was similar to another study in which patients' satisfaction was determined by their visual outcome, quality of care during their hospital stay delivered by hospital staff, and the relevance of patient education. Therefore, cataract outputs and surgical quality outcomes need to be improved and, simultaneously eye health services monitoring, reporting systems, and quality assurance mechanisms should be established.

There were some limitations in this study. Some factors might have impacted the data quality. Elderly with 
cataracts might receive other information about cataracts like via radios and televisions, which could have affected the overall knowledge, attitude, and practice scores in intervention and control groups. However, it most likely did not create a major effect on the outcome because there was a similar effect in both groups. The intervention was conducted for three months followed by immediate after intervention and three months follow-up assessments, and the result may vary in comparing with prolonged intervention. Like any study, as it was a quasi-experimental study, the allocation of participants to the intervention and control groups were lack of randomization, and the results of this study have limitations and are not generalizable to all areas in Myanmar. Long-term studies in other places are recommended.

\section{Conclusion}

The results of the study provided useful information to reduce the disparity in primary eyecare interventions which is of public health concern. Knowledge and attitude levels of the intervention group were significantly higher after the intervention. It indicated the need for specific interventions to improve eye health education in the community. As a result, higher use of eyecare was observed in both groups. Next, most patients followed the referral guide and went to government hospitals, but some sought eyecare at private hospitals. The national program might want to develop increased access to cataract services by integrating with other primary health services at least at provincial hospital level. Many patients with cataracts who used eyecare services were satisfied with the operation or treatment received and the visual outcome. In contrast, this door-to-door education about eye health to improve knowledge, attitude, and use of eyecare services among patients with cataracts, has shown absolute success in improving eye status in a rural community. Costeffectiveness studies should be pursued to test the feasibility of interventions in other resource-limited settings.

\section{Acknowledgments}

This research was financially supported by the 90th Anniversary of Chulalongkorn University Fund (Ratchadapiseksomphot Endowment Fund).

\section{Disclosure}

The authors report no conflicts of interest in this work.

\section{References}

1. World Health Organization. Ageing and health. Geneva: WHO; 2018. Available from: https://www.who.int/news-room/fact-sheets/detail/ ageing-and-health. Accessed January 25, 2021.

2. World Health Organization. World report on vision. Geneva: WHO; 2019. Available from: https://www.who.int/news-room/detail/08-10-2019-wholaunches-first-world-report-on-vision. Accessed January 25, 2021.

3. Bourne RRA, Flaxman SR, Braithwaite T, et al.; Vision Loss Expert Group. Magnitude, temporal trends, and projections of the global prevalence of blindness and distance and near vision impairment: a systematic review and meta-analysis. Lancet Glob Health. 2017;5 (9):e888-97. doi:10.1016/S2214-109X(17)30293-0.

4. Ackland P, Resnikoff S, Bourne R. World blindness and visual impairment: despite many successes, the problem is growing. Community Eye Health. 2017;30(100):71-73.

5. World Health Organization. World report on vision. Geneva: WHO 2019. Available from: https://apps.who.int/iris/bitstream/handle 10665/328717/9789241516570-eng.pdf. Accessed January 25, 2021.

6. Li LS, Ge ZY, Lohfeld L, et al. Knowledge, attitudes and practices related to seeking medical eyecare services by adults with moderate-to-severe visual impairment in rural Yueqing, Wenzhou, China: a cross-sectional survey. Int $J$ Ophthalmol. 2020;13 (7):1115-1123. doi:10.18240/ijo.2020.07.16

7. Pokharel GP, Khanna R Prevention of blindness in Myanmar: situation analysis and strategy for change. International Agency for Prevention of Blindness and Standard Chartered Bank (SCB); 2013. Available from: https://www.iapb.org/wp-content/uploads/2020/10 Prevention-of-Blindness-in-Myanmar_Situational-Analysis-Strategyfor-Change_0.pdf. Accessed January 25, 2021.

8. Ormsby GM, Mörchen M, Fotis K, Skiba DG, Chim C, Keeffe JE. Barriers to the uptake of cataract surgery and eye care after community outreach screening in Takeo province, Cambodia. Asia Pac J Ophthalmol. 2017;6(3):266-272. doi:10.22608/APO.2015127

9. Abdullah KN, Al-Sharqi OZ, Abdullah MT. Barriers to the uptake of eye care services in developing countries: a systematic review of interventions. Health Educ J. 2013;72(6):742-754. doi:10.1177/ 0017896912461193

10. Bâ E-H, Pitt C, Dial Y, et al. Implementation, coverage and equity of large-scale door-to-door delivery of Seasonal Malaria Chemoprevention (SMC) to children under 10 in Senegal. Sci Rep. 2018;8(1):5489. doi:10.1038/s41598-018-23878-2

11. Desrochers RE, Siekmans K, Berti PR, et al. Effectiveness of postcampaign, door-to-door, hang-up, and communication interventions to increase long-lasting, insecticidal bed net utilization in Togo (2011-2012): A cluster randomized, control trial. Malaria J. 2014;13 (1):260. doi:10.1186/1475-2875-13-260

12. Makin JK, Francis KL, Polonsky MJ, Renzaho AMN. Interventions to increase blood donation among ethnic/racial minorities: a systematic review. J Environ Public Health. 2019;2019 (Apr):6810959. doi:10.1155/2019/6810959

13. Ministry of Health and Sports, Myanmar. Report of rapid assessment of avoidable blindness survey. Myanmar; 2018. Available from: https://eyemyanmar.com/rapid-assessment-and-avoidable-blindness$\mathrm{raab} /$. Accessed January 25, 2021.

14. Chow S-C, Shao J, Wang H. Sample Size Calculation in Clinical Research. Chapman \& Hall/CRC; 2008.

15. Liu T, Congdon N, Yan X, et al. A randomized, controlled trial of an intervention promoting cataract surgery acceptance in rural China: the Guangzhou uptake of surgery trial (GUSTO). Invest Ophthalmol Vis Sci. 2012;53(9):5271-5278. doi:10.1167/iovs.12-9798

16. Ko KK, Pumpaibool T, Wynn MMM, Win Y, Aung PL, Kyi TM. Prevalence and risk factors of eye problems among older people in central tropical region, Naypyitaw Union Territory, Myanmar. Int Healthc Res J. 2019;3(2):68-75. doi:10.26440/IHRJ/ 0302.05.521080 
17. Folstein MF, Folstein SE, McHugh PR. "Mini-mental state". A practical method for grading the cognitive state of patients for the clinician. J Psychiatr Res. 1975;12(3):189-198. doi:10.1016/ 0022-3956(75)90026-6

18. Lay KMM, Oo TT, Sint WLL, et al. Subclinical thyroid dysfunction and cognitive function in Myanmar elderly. Myanmar Health Sci Res J. 2018;30(3):223-228.

19. Shah SP, Gilbert CE, Razavi H, Turner EL, Lindfield RJ. Preoperative visual acuity among cataract surgery patients and countries' state of development: a global study. Bull World Health Organ. 2011;89:749-756. doi:10.2471/BLT.10.080366

20. Khandekar R, Harby SA, Harthy HA, Lawatti JA. Knowledge, attitude and practice regarding eye complications and care among Omani persons with diabetes - A cross sectional study. Oman J Ophthalmol. 2010;3(2):60-65. doi:10.4103/0974-620X.64228

21. Livingston PM, McCarty CA, Taylor HR. Knowledge, attitudes, and self care practices associated with age related eye disease in Australia. $\mathrm{Br} J$ Ophthalmol. 1998;82(7):780-785. doi:10.1136/ bjo.82.7.780

22. Joshi A, Kale S, Chandel S, Pal DK. Likert scale: explored and explained. Curr J Appl Sci Technol. 2015;7:396-403. doi:10.9734/ BJAST/2015/14975
23. Adams NE. Bloom's taxonomy of cognitive learning objectives. $J$ Med Libr Assoc. 2015;103(3):152-153. doi:10.3163/15365050.103.3.010

24. Lee H, Jang YJ, Lee HK, Kang HY. Patient awareness of cataract and age-related macular degeneration among the Korean elderly: a population-based study. Korean J Ophthalmol. 2017;31(6):557-567. doi:10.3341/kjo.2017.0025

25. Nishad N, Hewage SA, Arulmoly K, et al. Barriers for cataract treatment among elderly in Sri Lanka. Curr Gerontol Geriatr Res. 2019;2019:6262456. doi:10.1155/2019/6262456

26. Burnett AM, Yashadhana A, Lee L, Serova N, Brain D, Naidoo K. Interventions to improve school-based eye-care services in low- and middle-income countries: a systematic review. Bull World Health Organ. 2018;96(10):682-694D. doi:10.2471/BLT.18.212332

27. Meda N, Bognounou V, Seni E, Daboue A, Sanfo O. Cataract in Burkina Faso: factors of choice between modern and traditional surgical procedures. Med Trop (Mars). 2005;65(5):473-476.

28. Conner-Spady BL, Sanmugasunderam S, Courtright P, McGurran JJ, Noseworthy TW. Steering Committee of the Western Canada Waiting List Project. Determinants of patient satisfaction with cataract surgery and length of time on the waiting list. $B r J$ Ophthalmol. 2004;88 (10):1305-1309. doi:10.1136/bjo.2003.037721
Clinical Ophthalmology

\section{Publish your work in this journal}

Clinical Ophthalmology is an international, peer-reviewed journal covering all subspecialties within ophthalmology. Key topics include: Optometry; Visual science; Pharmacology and drug therapy in eye diseases; Basic Sciences; Primary and Secondary eye care; Patient Safety and Quality of Care Improvements. This journal is indexed on PubMed

\section{Dovepress}

Central and CAS, and is the official journal of The Society of Clinical Ophthalmology (SCO). The manuscript management system is completely online and includes a very quick and fair peer-review system, which is all easy to use. Visit http://www.dovepress.com/ testimonials.php to read real quotes from published authors. 